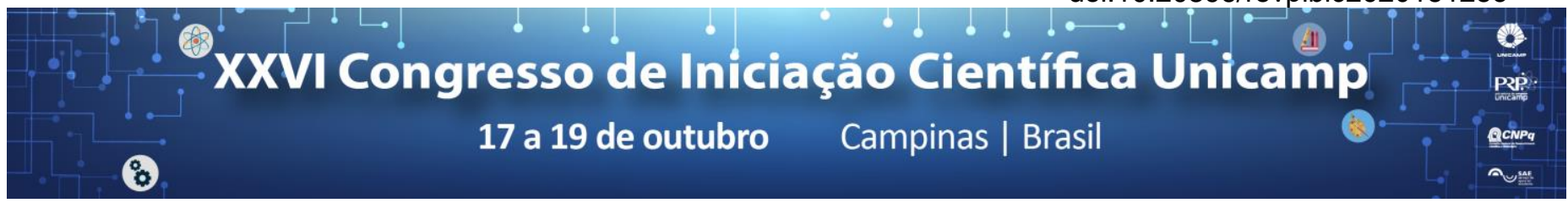

\title{
Sensor de temperatura chipless baseado nas propriedades de retrodifusão de uma antena.
}

\section{Tathiane Cabreira Ungari, Gilberto T. Santos-Souza e Prof. Dr. Leonardo L. Bravo-Roger.}

\section{Resumo}

Este projeto visa a implementação de um sensor de radiofrequência capaz de monitorar a temperatura ambiente. $O$ dispositivo a ser implementado não precisa de bateria nem de nenhum circuito integrado para funcionar e pode ser integrado a uma etiqueta passiva de sistemas de RFID. Seu princípio de funcionamento baseia-se na retro-dispersão de uma antena, isto traz a vantagem de que a medição pode ser realizada a distância.

\section{Palavras-chave:}

tag chipless, sensores de RF e RFID time domain .

\section{Introdução}

Foi concebido um sensor em forma de tag de RFID chipless, acoplando uma antena planar a uma linha de transmissão de impedância Z0, terminada em uma resistência de carga que varia com temperatura, ou seja um termistor. O nível de reflexão na carga depende do descasamento entre o valor da resistência do termistor (que é uma função de temperatura) e a impedância característica da linha. A temperatura é medida a certa distância da tag, a partir do nível de amplitude do sinal retro-difundido

\section{Resultados e Discussão}

O primeiro resultado obtido foi a realização no HFSS do projeto e simulação de uma antena monopolo circular, Figura 1. [1] Essa antena foi ligada a uma linha de demora terminada num termistor, Figura 2, cuja resistência varia com temperatura. Medindo-se o sinal retro-dispersado pela antena é possível estimar a temperatura do ambiente. $\mathrm{O}$ excelente desempenho da antena foi avaliado através da perda de retorno $S_{11}$ (deve ser menor que $-10 \mathrm{~dB}$ ) e de seu padrão de radiação [2], como mostra Figura 3. Espera-se que os resultados experimentais estejam de acordo com as simulações.

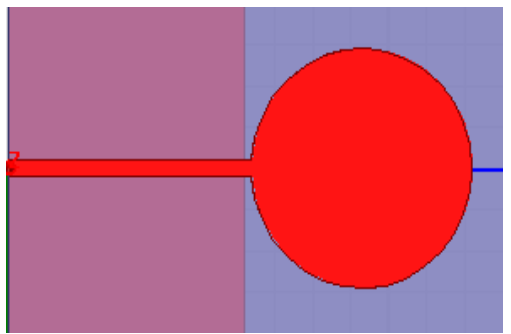

Figura 1. Antena monopolo circular projetada

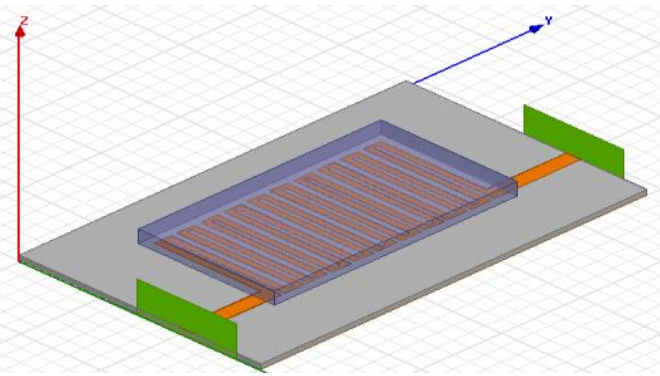

Figura 2.Linha de demora terminada em um termistor

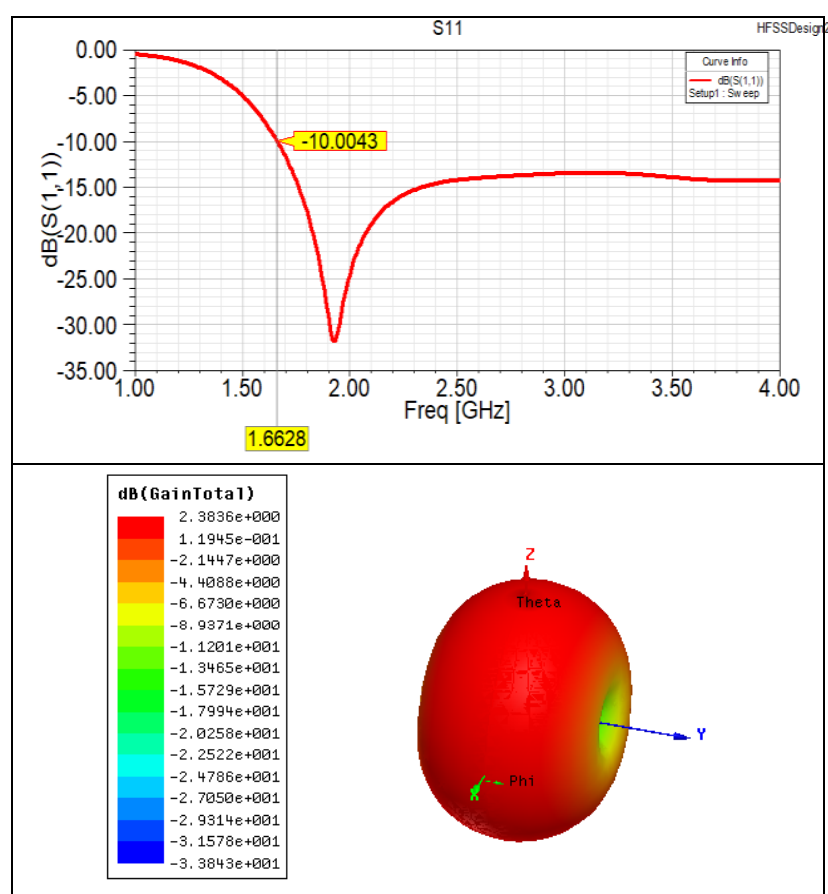

Figura 3.Análise da perda de retorno e Padrão de radiação para $1.6628 \mathrm{GHz}$ na antena monopolo circular.

\section{Conclusões}

Um sensor de temperatura baseado em radiofrequência foi concebido. Seu funcionamento não precisa de baterias nem de nenhum circuito integrado. Rigorosas simulações eletromagnéticas mostraram sua viabilidade. O nível de sinal recebido proveniente da antena sensora a uma distância remota, permite estimar a temperatura do ambiente no local onde o sensor está situado.

\section{Agradecimentos}

Agradeço ao meu orientador Leonardo L. Bravo-Roger, ao meu co-orientador Gilberto T. Santos-Souza, ao Julio César Avelino pela parceria, à Unicamp e ao CNPq.

${ }^{1}$ Schantz, H. G., "Introduction to ultra-wideband antennas", 4811 Cove Creek Drive, Brownsboro, AL

${ }^{2}$ Gilberto T. SantosSouza, Andreia Ap. de C. Alves, Hugo E. Hernandez-Figue roa, Leonardo L. Bravo

Roger,"Numerical Determination of Frequency Guard Band Resonances for C hipless RFID Tags", IEEE RFID Brasil , 2014 